\title{
Salvage therapies in relapsed and/or refractory myeloma: what is current and what is the future?
}

\author{
This article was published in the following Dove Press journal: \\ OncoTargets and Therapy \\ 5 August 2016 \\ Number of times this article has been viewed
}

\author{
Nishitha Thumallapally' \\ Hana Yu' \\ Divya Asti' \\ Adarsh Vennepureddy' \\ Terenig Terjanian ${ }^{2}$ \\ 'Department of Internal Medicine, \\ ${ }^{2}$ Division of Hematology and \\ Oncology, Staten Island University \\ Hospital, New York, NY, USA
}

\begin{abstract}
The treatment landscape for multiple myeloma (MM) is evolving with our understanding of its pathophysiology. However, given the inevitable cohort heterogeneity in salvage therapy, response to treatment and overall prognoses tend to vary widely, making meaningful conclusions about treatment efficacy difficult to derive. Despite the hurdles in current research, progress is underway toward more targeted therapeutic approaches. Several new drugs with novel mechanism of action and less toxic profile have been developed in the past decade, with the potential for use as single agents or in synergy with other treatment modalities in MM therapy. As our discovery of these emerging therapies progresses, so too does our need to reshape our knowledge on knowing how to apply them. This review highlights some of the recent landmark changes in MM management with specific emphasis on salvage drugs available for relapsed and refractory MM and also discusses some of the upcoming cutting-edge therapies that are currently in various stages of clinical development.
\end{abstract}

Keywords: multiple myeloma, novel drugs, relapsed and refractory myeloma, salvage chemotherapy

\section{Introduction}

Multiple myeloma (MM) is a plasma cell disorder representing $1.5 \%$ of all cancers and up to $13 \%$ of all hematologic malignancies worldwide. ${ }^{1}$ According to the American Cancer Society, 30,330 new cases of myeloma are expected to be diagnosed in 2016. ${ }^{2}$ Although myeloma is usually responsive to cytotoxic therapy in all stages, ie, in initial and relapsed, responses are often ephemeral, mandating the development of new therapeutic targets and more successful combination therapies. Over the years, notable progress has been made in autologous stem cell transplantation (ASCT) along with the introduction of several breakthrough drugs, including newer generation immunomodulators and proteasome inhibitors (PIs), which led to a significant increase in response rate of those affected as well as survival rate. ${ }^{3}$ In fact, 5-year survival rates have almost doubled, increasing from $27 \%$ to $47 \%$ between 1989 and 2010, respectively. ${ }^{4}$

Indeed, even with these enormous headways in the management of the disease, MM still remains a serious malady with many patients eventually developing treatment resistance. ${ }^{5}$ In addition, response time generally decreases with subsequent number of treatment lines. ${ }^{6}$ Overcoming this challenging nature of the disease remains a herculean task, with an increasing pressure to bring in other PIs and immunomodulatory drugs (IMiDs) as well as drugs with a niche mechanism of action which are effective even in progressed stages of myeloma. Currently available and investigational drugs for the treatment of MM are listed in Table 1. This review highlights some of the landmark
Correspondence: Nishitha Thumallapally Department of Internal Medicine, Staten Island University Hospital, 475 Sea View Avenue, Staten Island, New York, NY 10305, USA

Tel + I 4049068530

Email nishithareddy99@gmail.com 
Table I Snapshot of current and upcoming therapies

\begin{tabular}{ll}
\hline Drug category & $\begin{array}{l}\text { Current and } \\
\text { emerging drugs }\end{array}$ \\
\hline PI & BTZ \\
CFZ \\
Ixazomib \\
Oprozomib \\
Immunomodulatory agent & Thalidomide \\
& Lenalidomide \\
HDACi & Pomalidomide \\
& Panobinostat \\
Monoclonal antibody & Vorinostat \\
& Daratumumab \\
& Elotuzumab \\
KSP inhibitor & BT062 \\
PI3K-AKT-mTOR inhibitor & BBI090I \\
CAR T-cells & Filanesib \\
Vaccine therapy & Afuresertib \\
\hline Abbreiatons BTZ & \\
\hline
\end{tabular}

Abbreviations: BTZ, bortezomib; CFZ, carfilzomib; CAR, chimeric antigen receptor; $\mathrm{HDACi}$, histone deacetylase inhibitor; $\mathrm{KSP}$, kinesin spindle protein; Pl, proteasome inhibitor.

changes in the MM management with specific emphasis on salvage drugs available for relapsed and refractory MM (RRMM) and discusses some of the new and emerging drugs that are currently in various stages of clinical development.

\section{Definitions}

Traditionally, active MM diagnosis required confirmation of end-organ damage using the CRAB criteria (hypercalcemia, renal insufficiency, anemia, bone lesion). ${ }^{7}$ Based on this assessment, patients who did not exhibit any signs of end-organ damage, but showed evidence of clonal plasma cell proliferation, were classified as having either monoclonal gammopathy of undetermined significance or smoldering MM. Because of slow progression and less aggressive nature of monoclonal gammopathy of undetermined significance and smoldering MM, most of the patients in this disease stage were not treated, due to the finite number of safe treatment options available and lack of curability at that time. Currently, given that bone marrow and myeloma pathogenesis microenvironments are clearly defined, and a number of safer therapies have become available, these limitations no longer apply. To enhance the early diagnosis of the condition, the International Myeloma Working Group carried out progressive revision of MM criteria to avoid early occurrence of end-organ damage. ${ }^{8}$ The aim of this initiative was to include all patients who did not meet the CRAB criteria but had suspected early presence of clonal bone marrow plasma cells. The current criteria for diagnosing MM are summarized in Table $2 .^{8}$

\section{Risk stratification}

The initial step in any treatment pertains to the assessment of patient eligibility. In particular, it is not possible to make even a speculative prognosis before conducting risk stratification. This assessment includes careful consideration of the disease stage, performance status, and patient's age. Detecting biological mutations by the use of fluorescence hybridization in situ and conventional karyotyping is also usually performed when stratifying the disease in terms of the risk to the patient. ${ }^{9,10} \mathrm{MM}$ has various molecular subtypes that are all unique in response and presentation of

Table 2 Revised diagnostic criteria for MM

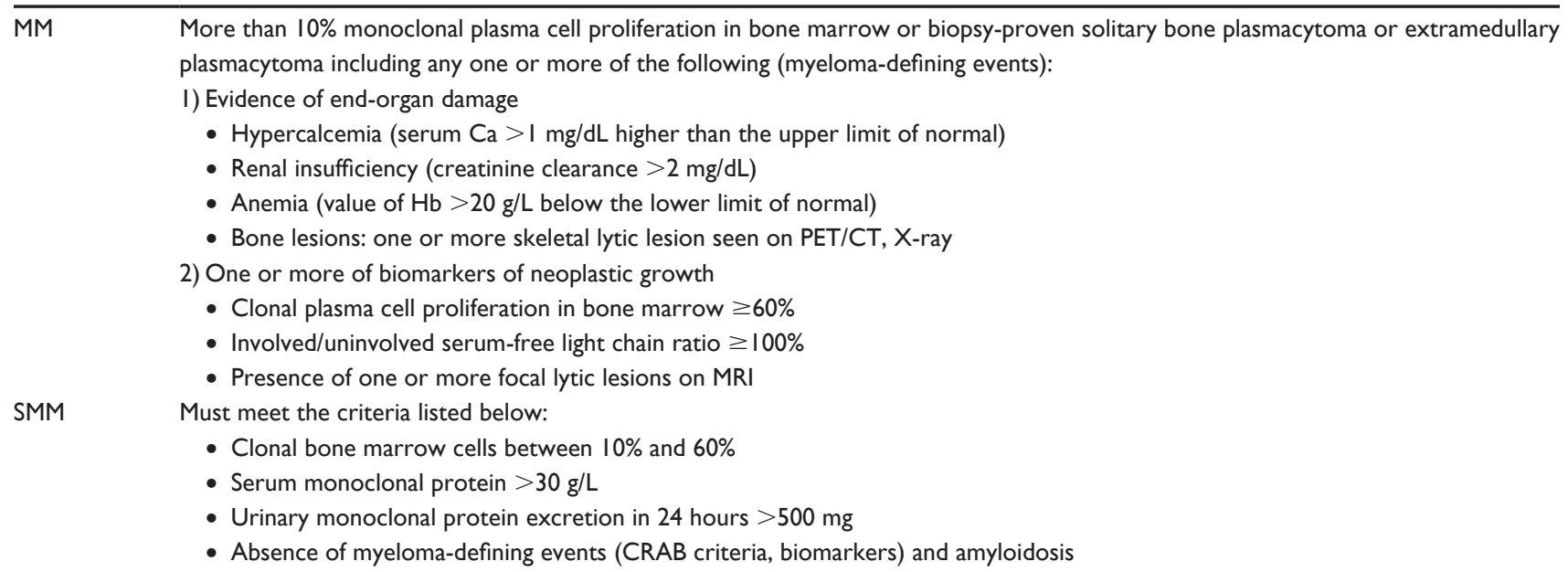

Note: Reprinted from Lancet Oncol, I5(I2). Rajkumar SV, Dimopoulos MA, Palumbo A, et al. International myeloma working group updated criteria for the diagnosis of multiple myeloma. Pages e538-e548. Copyright 2014, with permission from Elsevier. ${ }^{8}$

Abbreviations: CT, computed tomography; MM, multiple myeloma; MRI, magnetic resonance imaging; PET, positron emission tomography; SMM, smoldering MM; $\mathrm{Hb}$, hemoglobin; CRAB, Hypercalcemia, Renal insufficiency, Anemia, Bone lesions. 
disease. A good example of this distinctive presentation is the trisomic MM that responds appropriately to therapies that are lenalidomide based. ${ }^{11,12}$ At the same time, researchers have demonstrated that $\mathrm{t}(4 ; 14) \mathrm{MM}$ requires induction with bortezomib (BTZ) and suitable maintenance for successful outcomes. ${ }^{13,14}$ With respect to clinical presentation, $\mathrm{t}(4 ; 14)$ MM has been found to display lower rates of predilection of bone disease during diagnosis. On the other hand, association between $\mathrm{t}(14 ; 16) \mathrm{MM}$ with high serum-free light chain levels has frequently been reported, and the available evidence suggests that it may also lead to increased risks of acute renal failure during the diagnosis. ${ }^{15}$

In addition to cytogenetics, in recent years, many useful technological advances have been made, allowing exploration of genomic variability of specific malignant cells using gene expression profiles. Among these, the most notable are myPRS, SKT-92, and M3P. ${ }^{16-19}$ However, due to their novelty, very little empirical evidence regarding their value in predicting prognosis and long-term survival of patients more accurately, presently exists.

\section{Response criteria}

For the optimal understanding of the management of myeloma, it is also important to know the definitions of relapse and disease progression, set by the International Myeloma Workshop Consensus Panel, which are outlined in Table $3 .^{20}$

\section{Current treatment options for RRMM}

The current treatment standards for patients with RRMM include either rechallenging the disease with salvage chemotherapy or hematopoietic stem cell transplant. At present, the role of ASCT and post-transplant consolidation/ maintenance therapy remains unclear. Nonetheless, it is believed that these treatment options can be safely offered in specific cases. Historically, RRMM was treated by cytotoxic combination chemotherapy using melphalan, doxorubicin, or cyclophosphamide with dexamethasone or prednisone to reduce tumor burden prior to transplantation. However, high risk of long-term complications, such as secondary leukemia and myelodysplastic syndrome, necessitated the search for more effective and less toxic combinations. The research into new forms of therapy has taken into consideration drug resistance issues, along with matters pertaining to clonal evolution of disease. Currently, novel and less lethal emerging therapies are being tested as a part of several clinical trials, with or without the addition of stem cell transplantation. Moving forward, this review explains several chemotherapy options available currently for RRMM.

\section{Chemotherapy: monotherapy and combination therapy Novel Pls}

Proteolysis of cellular proteins is a highly regulated complex process and is important in maintaining cellular function and homeostasis. This process is streamlined by proteasomes, which selectively destroy proteins that are covalently labeled with ubiquitins through the ubiquitin proteasome pathway (UPP). ${ }^{21}$ Defects within this pathway could result in numerous diseases, including various malignancies. The UPP pathway consists of two essential steps, namely ubiquitin tagging and proteolytic degradation by the $26 \mathrm{~S}$ proteasome, which is composed of 20S core and 19S regulator. The first step, ubiquitin tagging, includes the binding of an E1 ubiquitin-activating enzyme with ubiquitin, and the subsequent transfer of ubiquitin to protein by an E3 ubiquitin ligase. In the second step, the ubiquitin molecules are released and the unfolded protein is released into the inner chamber of the $26 \mathrm{~S}$ proteasome. In this review, chymotrypsin-like, trypsin-like, and caspase-like enzymes catalyze the proteins to yield small peptides (Figure 1). ${ }^{21}$ Initially, PIs were probes facilitating research on the catalytic activity of proteasomes.

Table 3 Defining myeloma

\begin{tabular}{ll}
\hline Category & Definition \\
\hline PD & At least $25 \%$ increase from nadir in any of the following: \\
& - Serum $M$ protein (absolute increase must be $\geq 0.5 \mathrm{~g} / \mathrm{dL})$ \\
& - Urine $M$ protein (absolute increase must be $\geq 200 \mathrm{mg} / 24$ hours) \\
& - Difference between involved and uninvolved serum FLC levels (absolute increase must be $>$ I0 mg/dL) \\
Primary refractory MM & No response to either primary or salvage therapy in patients who never achieved even minimal response \\
Refractory MM & No response to either primary or salvage therapy or showing progression within 2 months of last therapy \\
Relapsed MM & Starting salvage therapy, after being off treatment \\
RRMM & No response while on salvage regimen or signs of progression within 2 months of last therapy in patients who improved \\
Double-refractory MM & at some point in disease course \\
\hline
\end{tabular}

Abbreviations: BTZ, bortezomib; FLC, free light chain; MM, multiple myeloma; PD, progressive disease; RRMM, relapsed and refractory MM. 


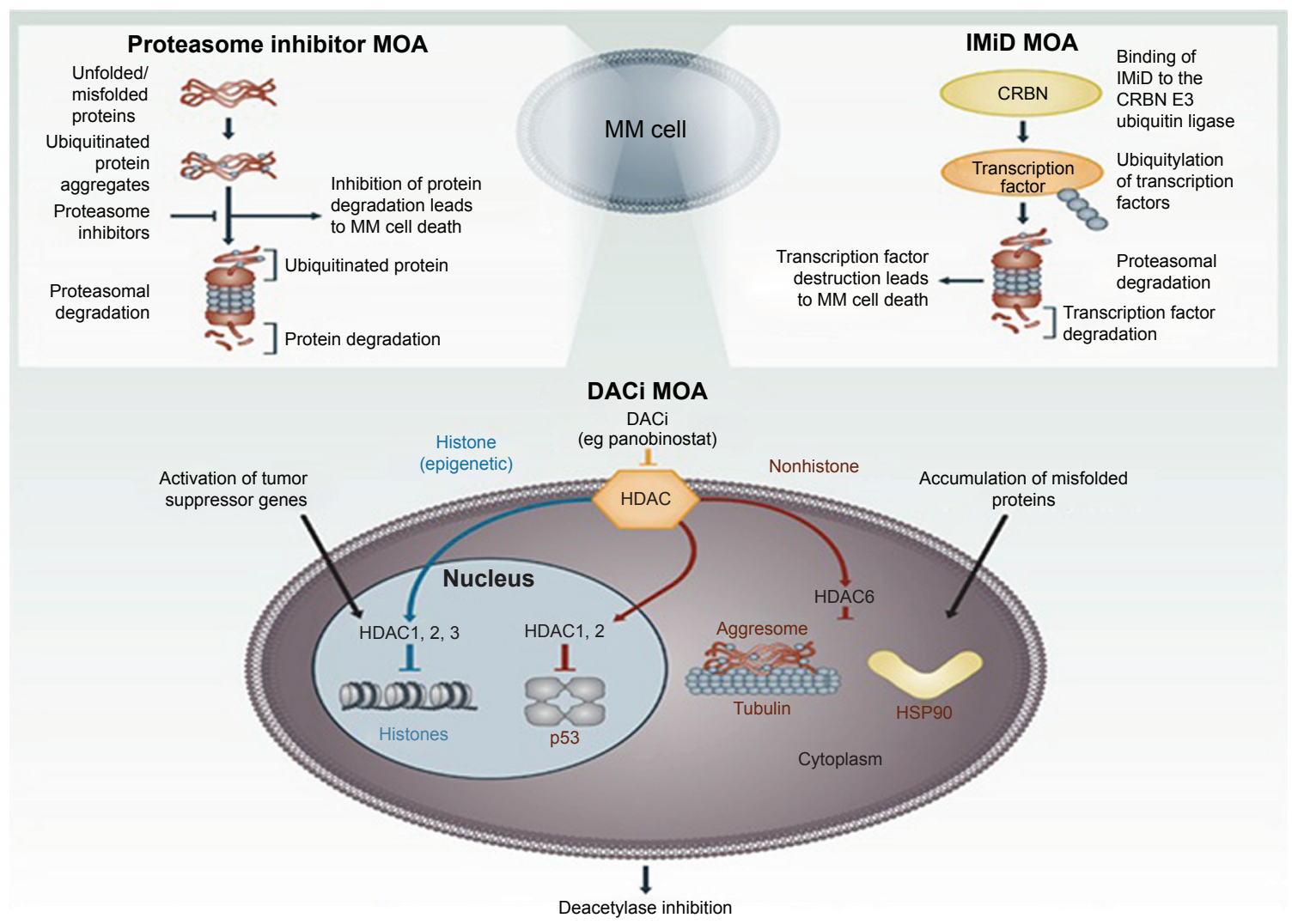

Figure I Mechanism of action of Pls, immunomodulators, and HDACi.

Notes: Proteasomes are intracellular structures which catabolize proteins that are marked with ubiquitin. PI block this mechanism of action causing accumulation of proteins triggering cell death. New molecular target identified for IMiD is cereblon, which is a key component of E3 ubiquitin ligase. This binding catalyzes ubiquitination of transcription factors IKZFI/IKZF3 eventually degrading them. IMiDs also modulate and inhibit angiogenesis and activate NK cells. HDAC enzymes regulate acetylation of the N-terminals of histones and other transcription factors. This is blocked by HDACi causing downregulation of protein expression. HDAC is also known to activate aggresome-proteasome pathway, which is blocked by HDACi. Reprinted by permission from Macmillan Publisher Ltd: Bone Marrow Transplant. Cornell RF, Kassim AA. Evolving paradigms in the treatment of relapsed/refractory multiple myeloma: increased options and increased complexity. 20I6;5I(4):479-49I. ${ }^{95}$ Copyright 2016.

Abbreviations: DAC, deacetylase; DACi, deacetylase inhibitor; HDAC, histone deacetylase; HDACi, histone deacetylase inhibitor; IMiD, immunomodulatory drug; MM, multiple myeloma; MOA, mechanism of action; NK, natural killer; PI, proteasome inhibitor.

Thereafter, their critical role in cell function heralded their role as potential therapeutic agents.

The first mechanism of action identified in PIs was the inhibition of the inflammation-associated protein NFKB, a transcription factor that plays a critical role in carcinogenesis by activating angiogenesis, proliferation, migration, and suppression of apoptosis. In the cytoplasm, NFKB is bound to its inhibitor IKB and is activated only when I $\mathrm{KB}$ undergoes proteolysis..$^{22}$ The inhibition of proteasome activity prevents the proteolytic cleavage of IKB and subsequently affects the activation and translocation of NFKB to the nucleus, thereby preventing the activation of downstream pathways. In addition, noteworthy is proteasome inhibition that leads to accumulation and aggregation of misfolded proteins in endoplasmic reticulum, which results in stress permitting the signaling to switch from pro-survival to pro-apoptotic in the cells. ${ }^{23}$

PIs also affect UPP-regulated DNA repair mechanisms such as nucleotide excision repair, postreplication repair, and homologous recombination, by depleting the available nuclear ubiquitin. This results in an accumulation of nondegraded polyubiquitinated proteins, and consequently less free ubiquitin in the cell. ${ }^{24}$ Concurrently, the reduced levels of free ubiquitin in the cell lead to a loss of monoubiquitinated histones within the nucleus, thereby affecting DNA repair. PIs sensitize tumor cells to various therapies. Proteasome inhibition is also associated with angiogenesis inhibition by affecting the secretion of vascular endothelial growth factor (VEGF) and at the same time causes upregulation of pro-apoptotic molecules such as p53, Bcl-2-associated X protein, and NOXA along with the reduction in the levels of anti-apoptotic proteins such as Bcl-2 inhibitor (inhibitors of apoptosis protein). ${ }^{25}$

BTZ is a reversible dipeptidyl-boronic-acid-based specific PI that targets the chymotrypsin- and caspase-like active sites. The efficacy and safety of BTZ were established through a number of important clinical trials (Table 4). It was initially approved by the Food and Drug Administration (FDA) in 2003 for refractory MM and subsequently expanded for use in combination therapy in the first-line setting and its role is 
Table 4 Landmark trials of BTZ

\begin{tabular}{|c|c|c|c|c|c|c|c|}
\hline \multirow[t]{2}{*}{ Trial } & \multirow[t]{2}{*}{ Phase } & \multirow[t]{2}{*}{ Patients (N) } & \multirow{2}{*}{$\begin{array}{l}\text { IMiD } \\
\text { exposed }\end{array}$} & \multirow{2}{*}{$\begin{array}{l}\text { PI } \\
\text { exposed }\end{array}$} & \multicolumn{3}{|c|}{ Efficacy } \\
\hline & & & & & ORR\% & $\begin{array}{l}\text { Median } \\
\text { PFS }\end{array}$ & $\begin{array}{l}\text { Median OS } \\
\text { (months) }\end{array}$ \\
\hline BTZ $1.3 \mathrm{mg} / \mathrm{m}^{2}+$ DEX $40 \mathrm{mg}(\text { CREST })^{85}$ & II & $54\left(1.3 \mathrm{mg} / \mathrm{m}^{2}: \mathrm{n}=26\right)$ & 0 & 0 & 50 & NA & 60 \\
\hline BTZ $1.3 \mathrm{mg} / \mathrm{m}^{2}+$ DEX $20 \mathrm{mg}(\text { SUMMIT) })^{86}$ & II & 202 & 83 & 0 & 27 & 7 & 16 \\
\hline BTZ $1.3 \mathrm{mg} / \mathrm{m}^{2}$ (or DEX $40 \mathrm{mg}$ ) (APEX) ${ }^{87}$ & III & 333 & 49 & 0 & 38 & 6.2 & NA \\
\hline BTZ $1-1.3 \mathrm{mg} / \mathrm{m}^{2}$ + thalidomide $50-200 \mathrm{mg} \pm$ DEX $20 \mathrm{mg}^{88}$ & $\mathrm{I} / \mathrm{II}$ & 85 & 74 & NA & 63 & 6 & 22 \\
\hline BTZ $1.0 \mathrm{mg} / \mathrm{m}^{2}$ + lenalidomide $15 \mathrm{mg}$ + DEX $20-40 \mathrm{mg}^{26}$ & II & 64 & 81 & 53 & 64 & 9.5 & 30 \\
\hline
\end{tabular}

Abbreviations: BTZ, bortezomib; DEX, dexamethasone; IMiD, immunomodulatory drug; NA, not available; ORR, overall response rate; OS, overall survival; PFS, progressionfree survival; PI, proteasome inhibitor.

currently being explored in the setting of post-ASCT maintenance therapy as well as induction therapy. Preclinical studies not only revealed the synergy between BTZ and lenalidomide but also potentiated the action of dexamethasone on tumor cells. This was tested in a Phase II trial in patients with relapsed MM or RRMM. When challenged with BTZ combined to lenalidomide and dexamethasone (VRd), these patients showed a remarkable progression-free survival (PFS) and overall survival (OS) duration lasting up to 9.5 months and 30 months, respectively (Table 4). This triplet combination showed increased, but manageable, toxicities including sensory neuropathy, fatigue, and neutropenia. ${ }^{26}$ This review laid the foundation for other ongoing combination studies with drugs that possess synergistic activity.

\section{Resistance to BTZ}

BTZ has been an effective therapy for MM; however, prolonged therapy could result in toxicity, peripheral neuropathy $(\mathrm{PN})$, and drug resistance mediated via the overexpression of the $\beta 5$-subunit, mutation of active drug-binding sites, or downstream upregulation of survival pathways. Three factors appear to be strongly associated with resistance toward PIs. First, there is mounting evidence on the role of deubiquitinating enzymes, USP14 and UCHL5, in survival and resistance to BTZ. These deubiquitinating enzymes could be deubiquitinating misfolded/unfolded proteins in MM, thereby reducing the stress levels. Second, autophagy might be a protective mechanism in MM cells. Induction of autophagy indirectly results in proteasome inhibition. Third, heat shock proteins (HSPs) appear to be a contributing factor in the resistance toward PIs. In vitro results have suggested that the inhibition of HSP70, an important component of the chaperone-mediated autophagy cytosolic chaperone complex, leads to the apoptosis of MM cells. ${ }^{27}$

These factors stimulated the development of other analogs of proteasome inhibitors with increased efficacy and decreased toxicity and at the same time overcoming bortezomib resistance.

\section{Second-generation Pls Carfilzomib}

Carfilzomib (CFZ) is a second-generation irreversible PI that binds on the proteasome to a site different from BTZ. It is a peptidyl epoxyketone and primarily inhibits the chymotrypsin-like activity at the $\beta S$-subunit of the core 20 S proteasome. ${ }^{28}$ Apart from triggering cell cycle arrest, inducing apoptosis, and activating stress response pathways in human tumor cell lines, CFZ has been shown to be active against BTZ -resistant cell lines. ${ }^{29}$

Two Phase II trials investigated the efficacy of singleagent activity of CFZ in patients refractory to BTZ and lenalidomide. The first Phase II trial (PX-171-003-A0) studied 46 patients on CFZ at a dose of $20 \mathrm{mg} / \mathrm{m}^{2}$ given intravenously for 2 days consecutively for 3 weeks, followed by 2 weeks of intermission. This constituted one cycle, and the study was designed to complete 12 cycles. Very favorable results (overall response rate [ORR] of $13 \%$ and median duration of response up to 7.3 months) led to the alteration of the study to incorporate more pretreated patients and extend dosing regimen. ${ }^{30}$ This extended single-arm, multi-center Phase II study (PX-171-003-A1) included 266 patients who had received a median of five prior anti-myeloma regimens. CFZ was administered at a starting dose of $20 \mathrm{mg} / \mathrm{m}^{2}$ in cycle 1 , followed by the escalated target dose of $27 \mathrm{mg} / \mathrm{m}^{2}$ in the cycles $2-12 .{ }^{28}$ ORR was $\sim 23 \%$ and observed in $36 \%$ of treated patients. These results prompted the fast-track approval of CFZ for the treatment of RRMM in patients who had received at least two prior treatments, including BTZ and immunomodulatory drug in July 2012. Dosing regimens of CFZ in BTZ naive patients were also investigated in another Phase II trial. ${ }^{31}$ In this review, patients who met the aforementioned criteria either received a starting dose of $20 \mathrm{mg} / \mathrm{m}^{2}$ for 12 cycles, each comprising of 28 cycle days (cohort 1), or $20 \mathrm{mg} / \mathrm{m}^{2}$ in cycle 1 , followed by the escalated target dose of $27 \mathrm{mg} / \mathrm{m}^{2}$ in the cycles 2-12 (cohort 2). The analysis of their results revealed an ORR of $42 \%$ and $52 \%$ in cohorts 1 and 2, respectively. According to the authors, 
BTZ -naive patients had a better response to CFZ delivered in an escalated mode.

The most common adverse effects noted in the safety analysis were fatigue (49\%), anemia (46\%), nausea (45\%), and thrombocytopenia (39\%). The results also demonstrated a clear superiority of this treatment option relative to BTZ in terms of inducing or worsening PN. More specifically, patients with preexisting neuropathy did not experience worsening of their symptoms following the CFZ therapy. CFZ is currently being tested in combination chemotherapy and in frontline settings, as listed in Table 5.

Data from Phase III ASPIRE study (aimed at comparing treatment consisting of the combination of $\mathrm{CFZ}$ and lenalidomide-dexamethasone with the effects of lenalidomide-dexamethasone alone in the relapsed setting) showed encouraging PFS rates (26.3 months vs 17.6 months; $P<0.001)$ in the CFZ group, further spiraling its way up as the most promising PI. ${ }^{32}$

In the ENDEAVOR trial, the aim was to assess the efficacy of CFZ and dexamethasone in comparison with the effects of a combination of BTZ and dexamethasone in patients with relapsed MM, revealing statistically significant and high PFS in the CFZ group (PFS 18.7 months vs 9.4 months). Although hematologic adverse effects are similar in both groups, hypertension, dyspnea, and cardiac failure were more frequently seen with CFZ in this trial. ${ }^{33}$ As these findings do not concur with those reported in other previous trials, they are of notable concern and thus require further monitoring and evaluation in the future studies.

In addition to the trials discussed earlier, two early-phase studies are also noteworthy, as their goal is to investigate the efficacy and safety of CFZ in frontline MM in combination with either thalidomide ${ }^{34}$ or lenalidomide ${ }^{35}$ and dexamethasone. These trials are important for gaining a better understanding of CFZ, and their findings may facilitate an expanded indication for this agent, as well as regulatory approval in the future.

ENDURANCE trial, which is a Phase III trial, is also of interest for the current discussion, as it involves 756 newly diagnosed patients with myeloma, with the aim of comparing CFZ triplet with BTZ triplet. ${ }^{36}$ Once its findings are reported, they are likely to help elucidate which PI is most appropriate for use in the frontline settings.

\section{Marizomib}

Findings of existing research studies suggest that marizomib, a novel PI, can be an effective replacement for BTZ. Results reported in 2012, pertaining to two parallel, Phase I, doseescalation studies conducted in Australia and the US, in which 34 patients diagnosed with RRMM took part, were highly encouraging. To note is the fact that $\sim 70 \%$ patients in this trial were BTZ refractory and still a partial response (PR) was observed in $20 \%$ of patients, when treated with marizomib. ${ }^{37}$ Most of the patients reported fatigue, dizziness,

Table 5 Key trials of second-generation Pls and immunomodulators

\begin{tabular}{|c|c|c|c|c|c|c|c|c|c|}
\hline \multirow[t]{2}{*}{ Trial } & \multirow[t]{2}{*}{ Phase } & \multicolumn{5}{|c|}{ Patients } & \multicolumn{3}{|c|}{ Efficacy } \\
\hline & & $\mathbf{N}$ & $\begin{array}{l}\text { IMid } \\
\text { exposed (\%) }\end{array}$ & $\begin{array}{l}\text { IMiD } \\
\text { refractory (\%) }\end{array}$ & $\begin{array}{l}\text { PI } \\
\text { exposed } \\
(\%)\end{array}$ & $\begin{array}{l}\text { PI } \\
\text { refractory } \\
(\%)\end{array}$ & $\begin{array}{l}\text { ORR } \\
\text { (\%) }\end{array}$ & $\begin{array}{l}\text { Median PFS } \\
\text { (months) }\end{array}$ & $\begin{array}{l}\text { Median OS } \\
\text { (months) }\end{array}$ \\
\hline CFZ $\left(20 \mathrm{mg} / \mathrm{m}^{2}\right)^{28}$ & II & 266 & 100 & NA & 100 & 73 & 23 & 3.7 & 15.6 \\
\hline $\begin{array}{l}\text { CFZ } 20-27 \mathrm{mg} / \mathrm{m}^{2}+\text { LEN } 25 \mathrm{mg}+ \\
\text { DEX } 40 \mathrm{mg}^{35}\end{array}$ & II & 52 & LEN: 73 & LEN: 44 & 81 & 25 & 77 & 15.4 & NA \\
\hline $\begin{array}{l}\text { CFZ } 20-27 \mathrm{mg} / \mathrm{m}^{2}+\text { LEN } 25 \mathrm{mg}+ \\
\text { DEX } 40 \mathrm{mg}(\text { ASPIRE) })^{32}\end{array}$ & III & 792 & LEN: 20 & NA & 66 & NA & 87 & 26.3 & NA \\
\hline $\begin{array}{l}\text { CFZ } 20-27 \mathrm{mg} / \mathrm{m}^{2}+\text { POM } 4 \mathrm{mg}+ \\
\text { DEX } 40 \mathrm{mg}^{89}\end{array}$ & $\mathrm{I} / \mathrm{II}$ & 72 & 100 & 100 & 87 & 70 & 64 & 12.0 & 16.3 \\
\hline $\begin{array}{l}\text { Xazomib (MLN9708) } 4 \mathrm{mg}+\text { LEN } 25 \mathrm{mg}+ \\
\text { DEX } 40 \mathrm{mg}^{39} 0.24-3.95 \mathrm{mg} / \mathrm{m}^{2}\end{array}$ & III & 722 & $\begin{array}{l}\text { LEN: } 12 \\
\text { THAL: } 44\end{array}$ & NA & 70 & NA & 78.3 & 20.6 & NA \\
\hline $\begin{array}{l}\text { POM } 4 \text { mg + DEX } 40 \text { mg (or POM } \\
4 \text { mg) }(\mathrm{MM}-002)^{51}\end{array}$ & II & 221 & 100 & 79 & 100 & 71 & 33 & 4.2 & 16.5 \\
\hline $\begin{array}{l}\text { POM } 4 \text { mg + low-dose DEX } 40 \text { mg (or } \\
\text { high-dose DEX } 40 \text { mg) (MM-003) }\end{array}$ & III & 302 & 100 & 95 & 100 & 79 & 31 & 4.0 & 12.7 \\
\hline $\begin{array}{l}\text { POM } 4 \text { mg + DEX } 40 \text { mg + } \\
\text { cyclophosphamide (POM + DEX) }\end{array}$ & II & 34 & $\begin{array}{l}\text { All patients: } \\
\text { LEN refractory }\end{array}$ & $\begin{array}{l}\text { All patients: } \\
\text { LEN refractory }\end{array}$ & NA & 24 & 65 & 9.2 & NA \\
\hline $\begin{array}{l}\text { POM }{ }^{91} \mathrm{I}-4 \mathrm{mg}+\mathrm{BTZ} \mathrm{I}-1.3 \mathrm{mg} / \mathrm{m}^{2}+ \\
\text { DEX } 20 \mathrm{mg}\end{array}$ & I & 28 & 100 & 100 & 100 & 0 & 71 & NA & NA \\
\hline
\end{tabular}

Abbreviations: BTZ, bortezomib; CFZ, carfilzomib; DEX, dexamethasone; IMiD, immunomodulatory drug; LEN, lenalidomide; NA, not available; ORR, overall response rate; OS, overall survival; PFS, progression-free survival; PI, proteasome inhibitor; POM, pomalidomide; THAL, thalidomide. 
and headache as the prevalent drug-related adverse effects. No evidence of PN or thrombocytopenia was noted. Preliminary data from these trials imply that the adverse effects of marizomib are quite different when compared with other PIs. Moreover, there is strong evidence that it is active in BTZrefractory patients. Following this research, the effectiveness of a twice-weekly regimen of marizomib $0.5 \mathrm{mg} / \mathrm{m}^{2}$ in combination with Pomalidomide low-dose dexamethasone is presently being investigated. ${ }^{38}$

\section{Ixazomib}

The preliminary data suggest that ixazomib produces durable responses in patients treated with other agents. The FDA approval of ixazomib (MLN9708) was based on the data yielded by the ongoing Phase III TOURMALINE-MM trial that included 722 patients across 26 countries. All patients included in the trial had received at least one prior therapy. In addition, $50 \%$ of the cohort had undergone a stem cell transplant and their condition was progressing at the time of their recruitment to the study. The reported results indicate that a triplet combination of ixazomib, lenalidomide, and dexamethasone resulted in a significant improvement in PFS which substantially exceeded the benefits of the therapy based on the combination of lenalidomide and dexamethasone (with the median PFS of 20.6 months vs 14.7 months; Table 6) ${ }^{39}$

\section{Oprozomib}

Oprozomib is an irreversible PI, which is currently being evaluated in Phase Ib/II studies as a single agent and in combination with dexamethasone for patients with RRMM and other hematologic malignancies. ${ }^{40}$

CEP18770 (delanzomib) is an oral/intravenous, reversible boronate peptide agent which has shown promising antitumor activity in mouse models, with some treated specimens experiencing complete regression and significant survival benefits. Subsequently, Phase I trial, in which 38 patients took part, yielded encouraging findings, as none exhibited neurotoxicity commonly associated with BTZ (Table 6). ${ }^{41,42}$

\section{Novel immunomodulators}

Immunomodulators (IMiDs) exhibit antitoxic effects by binding to cereblon, a key protein of the E3 ubiquitin ligase complex, resulting in rapid ubiquitination and subsequent degradation of transcription factors, IKZF3 and IKZF1, as shown in Figure $1 .{ }^{43}$ Immunomodulators also regulate cell adhesion and bone marrow angiogenesis by inhibiting VEGF, tumor necrosis factor- $\alpha$, interleukin-6, and interferon gamma, which in turn cause natural killer (NK) cell activation and NK cell-dependent cytotoxicity. ${ }^{44}$

Thalidomide was the first IMiD to emerge as a treatment option for MM. However, it is highly aggressive and

Table 6 Key trials on emerging novel therapies

\begin{tabular}{|c|c|c|c|c|}
\hline Name & $\begin{array}{l}\text { Mechanism } \\
\text { of action }\end{array}$ & Trial/phase & Primary end point & Combinations \\
\hline Oprozomib ${ }^{41,42}$ & Irreversible PI & NCT0I88I789, Phase Ib/II & ORR & LEN, DEX, CYC \\
\hline \multirow[t]{2}{*}{ Marizomib 37,38} & Irreversible PI & NCT02103335, Phase I & PR, ORR & POM, DEX \\
\hline & & NCT0046I045, Phase II & MTD, ORR & $\mathrm{NA}$ \\
\hline \multirow[t]{2}{*}{ Panobinostat ${ }^{58,59}$} & Pan HDACi & $\begin{array}{l}\text { NCT0I023308, Phase III } \\
\text { (PANAROMA I) }\end{array}$ & PFS, ORR & BTZ \\
\hline & & $\begin{array}{l}\text { NCTOI083602, Phase IV } \\
\text { (PANAROMA 2) }\end{array}$ & ORR & BTZ, DEX \\
\hline Elotuzumab ${ }^{65}$ & Anti-SLAMF7 & NCTOI239797, Phase III & ORR & LEN, DEX \\
\hline Daratumumab $^{67}$ & Anti-CD38 & NCT02076009, Phase III & ORR & LEN, DEX \\
\hline Isatuximab (SAR 65084) & Anti-CD38 & NCT0I749969, Phase lb & ORR & LEN, DEX \\
\hline Isatuximab (SAR 65084) & Anti-CD38 & NCT02332850, Phase lb & $\begin{array}{l}\text { Adverse events, Maximum } \\
\text { Tolerated Dose (MTD) }\end{array}$ & CFZ \\
\hline Isatuximab (SAR 65084) & Anti-CD38 & NCT02283775, Phase lb & Dose Limited Toxicity & POM \\
\hline Indatuximab ravtansine $e^{71}$ & Anti-CDI38 & NCT0I638936, Phase I/Ila & ORR & LEN, DEX \\
\hline Filanesib ${ }^{74}$ & KSP inhibitor & NCT02092922, Phase II & ORR & NA \\
\hline Pomalidomide ${ }^{92}$ & IMid & NCTOI734928, Phase III & PFS & BTZ, DEX \\
\hline CAR T-cell ${ }^{93}$ & Anti-BCMA & NCT022I5967, Phase I & Safety & CYC, FLU \\
\hline $\begin{array}{l}\text { Measles virus strain } \\
\text { (Edmonston })^{94}\end{array}$ & $\begin{array}{l}\text { Oncolytic } \\
\text { virus therapy }\end{array}$ & NCT02192775, Phase II & $\begin{array}{l}\text { Assess effectiveness as } \\
\text { measured by IMWG } \\
\text { guidelines }\end{array}$ & $\mathrm{N} / \mathrm{A}$ \\
\hline
\end{tabular}

Abbreviations: BCMA, B-cell maturation antigen; BTZ, bortezomib; CAR, chimeric antigen receptor; CFZ, carfilzomib; CYC, cyclophosphamide; DEX, dexamethasone; FLU, fludarabine; HDACi, histone deacytalase inhibitors; IMid, immunomodulators; IMWG, International Myeloma Working Group; KSP, kinesin spindle protein; LEN, lenalidomide; mAbs, monoclonal antibodies; MTD, Maximum Tolerated Dose; NA, not applicable; ORR, overall response rate; PFS, progression-free survival; PI, proteasome inhibitor; POM, pomalidomide; PR, partial response. 
is associated with considerable toxicity, particularly in older patients. This motivated researchers to explore potential analogs exhibiting greater clinical efficacy and better toxicity profile. Among the IMiDs that emerged from this effort, the most notable are lenalidomide (Revlimid) and pomalidomide (Pomalyst). In the past decade, these two agents were subjected to numerous trials investigating their effectiveness in the treatment of MM, which established their safety and efficacy profiles. Thus, this review focuses on key trials that have provided a solid conceptual foundation for the use of newer analogs of thalidomide in RRMM.

Thalidomide was first approved by the FDA in 2006. The decision was based on the results yielded by Phase III trial involving 207 newly diagnosed patients with MM who were randomly assigned to the treatment or control group, thus receiving a combination of thalidomide and dexamethasone vs dexamethasone alone. The results revealed that the patient response rates (based on serum or urine paraprotein measurements) were significantly higher in the combination arm than in the control group receiving dexamethasone alone (51.5\% vs $35.6 \%$, respectively, $P=0.025) .{ }^{45}$ Since the FDA approval, several trials using thalidomide as a single agent, or in combination with dexamethasone or melphalan and prednisone, have been conducted, and their findings confirm the benefits of this therapy mode. Thus, thalidomide is currently recommended for the treatment of newly diagnosed patients with MM in both the transplant-eligible and non-transplant eligible populations, as well as in patients with relapsed disease. Based on the available evidence, $\mathrm{PN}$ and venous thromboembolism are the main side effects stemming from the extended use of thalidomide. ${ }^{46}$

In 2006, the FDA also approved the more potent lenalidomide in combination with dexamethasone for the treatment of patients with MM who had received at least one prior therapy. The approval was based on the results yielded by the pooled analysis of two randomized, placebo-controlled Phase III trials, denoted as MM009 and MM010; the findings of which revealed longer PFS and OS in patients with RRMM. ${ }^{47,48}$ The incidence of thromboembolic events in these trials was reported at $16 \%$, where in prophylactic anticoagulation was not mandatory. In additional trials, the role of maintenance lenalidomide following the ASCT was also evaluated, and the results indicate the improvement in event-free survival. ${ }^{49}$

Pomalidomide is the most recent contribution to the development of IMiDs and is presently available in the market for the treatment of patients with RRMM. It is derived by adding an amino group to the fourth carbon of the phthaloyl ring of thalidomide, resulting in increased potency of both anti-inflammatory and antiangiogenic properties, accompanied by reduced toxicities..$^{50}$ Once its efficacy was ascertained in Phase I studies, pomalidomide was further evaluated in combination with dexamethasone. One such trial is a Phase II study involving patients with double-refractory myeloma; the findings of which indicate superior PFS in the pomalidomide/dexamethasone group, as shown in Table 5. In this trial, treatment was discontinued primarily due to myelosuppression, in particular, grade $>3$ neutropenia. ${ }^{51}$

Findings of the vital Phase III MM-003 trial also indicated longer PFS and OS in patients treated by pomalidomide/ low-dose dexamethasone compared with those who received high-dose dexamethasone therapy, which led to the accelerated approval by the FDA in 2013. Presently, pomalidomide is approved for the treatment of patients with MM who have received at least two prior therapies, including lenalidomide and BTZ, and have demonstrated disease progression on or within 60 days of completion of the last therapy. ${ }^{52}$ As a condition implicit to this accelerated approval, the FDA will require submission of the results of the clinical trial CC-4047-MM-007, a randomized Phase III trial examining the effects of treatment with 1) pomalidomide added to BTZ and low-dose dexamethasone compared with 2) a combination of BTZ and a low-dose dexamethasone in patients with previously treated MM, as shown in Table 6. Available evidence indicates that pomalidomide produces tolerable grade 3-4 side effects, with neutropenia, thrombocytopenia, and anemia being the most common. Pomalidomide is also currently being evaluated as a combination therapy in various trials aiming to elucidate its role in RRMM in the near future (Tables 5 and 6).

\section{Novel histone deacetylase inhibitors}

Epigenetic modification is defined as an alteration of gene expression without the alteration of DNA sequences. It is further characterized into two major types: DNA methylation and histone modification. ${ }^{53}$ Although aberrancy in DNA methylation is evident in MM pathogenesis, uncertainty prevails in its mechanism. On the other hand, histone acetylation is comparatively well defined. The lysine residues within the N-terminal of histone tails can undergo various chemical modifications, including acetylation, methylation, ubiquitination, phosphorylation, and sumoylation. ${ }^{54}$ The acetylation status of histones is controlled by the opposing actions of two classes of enzymes: histone acetyl transferases, which transfer acetyl groups to lysine residues in histones, and histone deacetylases (HDACs), which remove the acetyl groups (Figure 1). This acetylation status of histones further 
influences chromatin conformation, which in turn regulates the expression of tumor suppressors, oncogenic proteins, and transcription factors. ${ }^{54}$

Three standard HDAC classes (I, II, and IV) containing eleven HDACs have been identified thus far and are classified according to their homology to yeast proteins, subcellular location, and enzymatic activities. ${ }^{55}$ Recent studies have shown that the overexpression of specific HDAC isoenzymes, such as HDAC1-4, HDAC6, and HDAC11, is associated with decreased PFS in patients with MM. In addition, epigenetic silencing of tumor suppressor genes, such as GPX3, RBP1, SPARC, and TGRBI, is associated with decreased survival in MM.

Of all HDAC enzymes, HDAC6 needs a special mention. Apart from streamlining epigenetic modification, it plays a key role in the aggresome protein degradation pathway. This pathway is another alternative proteolytic process that allows myeloma cells to develop resistance to PIs such as BTZ. ${ }^{56}$ HDAC6 identifies proteins tagged with polyubiquitinated tails and targets them toward the dynein motor complex which in turn directs to the autophagosome for destruction. ${ }^{57}$ Consequently, in a therapy based on a combination of HDAC and BTZ, both agents work synergistically to increase the cytotoxicity in MM cells.

At present, several HDAC inhibitors (HDACi) are being evaluated as potential candidates for MM therapy. In clinical trials, panobinostat and vorinostat in particular have shown promising results. Thus, these agents are reviewed in the following sections in more detail, to elucidate their potential therapeutic effects and usage in the treatment of RRMM.

\section{Panobinostat}

Panobinostat is among one of the most potent pan-HDAC inhibitors in clinical development. It is believed to act primarily through epigenetic modulation of gene expression and inhibition of protein metabolism in the nanomolar range. In terms of the effects on all HDACs, potency of panobinostat is established to be at least tenfold greater than that observed in vorinostat, another nonselective HDACi. ${ }^{55}$ It is active against classes I, II, and IV HDAC enzymes.

On February 23, 2015, the FDA approved panobinostat for use in combination with BTZ and dexamethasone in the treatment of patients with MM who have previously received at least two drug regimens. ${ }^{55}$ The approval was based on the results yielded by the Phase III PANORAMA 1 trial that examined effectiveness of panobinostat, when administered in combination with BTZ and dexamethasone. ${ }^{58}$ The study sample was composed of 768 adult patients with RRMM who had received one to three prior treatments. The results demonstrated a clinically significant improvement in median PFS among the patients assigned to the panobinostat arm, which was statistically significantly greater relative to that observed in the placebo arm. Among the reported side effects, the most prominent were primarily gastrointestinal (diarrhea, nausea, and vomiting) and hematologic (thrombocytopenia) issues. However, the researchers cautioned that prolonged usage of panobinostat could result in cardiac toxicity, which could be a barrier to a wider application of this medication. Available evidence indicates that QTc prolongation and arrhythmias are the most likely cardiac issues, which are observed predominantly in elderly patients with MM. ${ }^{58}$

Following from this investigation, PANORAMA 2 was initiated. This single-arm Phase II trial aims at evaluating the effects of treatment comprised of adding panobinostat to BTZ and dexamethasone as a means of establishing whether BTZ-refractory patients respond to BTZ when HDACi is added. Among the 55 patients enrolled in this trial, ORR of $\sim 34.5 \%$ was noted, with a median response duration of $\sim 6$ months (Table 6). ${ }^{59}$

In addition to the aforementioned studies, several further trials are presently being conducted, with the goal of evaluating effectiveness of panobinostat in combination with other novel agents, such as next-generation protease inhibitors (CFZ or ixazomib), an IMiD (lenalidomide), and BTZ plus an IMiD (thalidomide or lenalidomide) with dexamethasone in relapsed/refractory MM. ${ }^{55}$

\section{Vorinostat}

Vorinostat is another nonselective HDACi that inhibits the enzymatic activity of HDACs, HDAC1, HDAC2, and HDAC3 (class I), and HDAC6 (class II) at nanomolar concentrations. ${ }^{57}$ This drug was approved for use in the US in 2006 and has since then been offered to patients with cutaneous T-cell lymphoma. Vorinostat has also been tested in patients with MM and has been shown to be a potent inducer of apoptosis in MM cells. When combined with BTZ, it has been shown to enhance inhibition of protein breakdown. Moreover, in clinical trials, patients have exhibited increased response. ${ }^{60,61}$ Of particular interest for the current investigation are VANTAGE 099 and VANTAGE 095 multicenter clinical trials that assessed the efficacy and safety of treatment based on a combination of vorinostat and BTZ in patients with relapsed or refractory MM.

In the VANTAGE 095 trial, an open-label, single-arm Phase IIb trial, 143 patients with heavily pretreated RRMM who had previously undergone a median of two treatment 
regimens were evaluated for efficacy of vorinostat in combination with BTZ. Study patients had disease that was refractory to BTZ and IMiD. Patients were treated until they started exhibiting signs of disease progression, showed evidence of unacceptable toxicities, or withdrew from the study. The primary end point was ORR ( $\geq P R$ ). This combination demonstrated an ORR of $17 \%$ with a median response duration of 6.3 months. The PFS and OS were 3.1 months and 11.2 months, respectively. ${ }^{62}$ This study was followed by VANTAGE 088 trial.

In the VANTAGE 088 trial, which was a Phase III randomized, double-blinded, placebo-controlled study, 637 patients, with a median of two previous treatments, were randomized to receive BTZ together with vorinostat or placebo (BTZ alone). As in VANTAGE 095 trial, patients were treated until disease progression, unacceptable toxicities, or withdrawal from the study. The primary end point for this trial was PFS, whereas secondary and exploratory end points included ORR ( $\geq P R)$, clinical benefit response (ORR + minimal response), OS, time to progression, and safety/tolerability. The study yielded findings indicating marked improvement in PFS in patients receiving the combination of vorinostat and BTZ compared with those who were treated with BTZ alone. Median PFS was 7.63 months in the vorinostat group, which was significantly higher than that in the placebo group (6.83 months). The ORR was also greater in the vorinostat group than the placebo group (56.2\% vs 40.6\%). ${ }^{61}$ At present, however, the vorinostat pharmaceutical manufacturer is not pursuing FDA approval for the treatment of MM. Nonetheless, its efficacy in combination with other myeloma agents is still being evaluated in clinical studies. Further research is clearly needed to define the role of vorinostat in RRMM as well as to determine its maximum-tolerated dose. Its side effects should also be explored, given the evidence of thrombocytopenia, diarrhea, nausea, fatigue, and anemia.

Because HDACs regulate a plethora of cellular functions, their use as multi-targeted therapeutic agents is appealing. Consequently, they have emerged as relevant clinical targets in MM treatment. In trials based on these drugs, especially when administered in combination with a PI, patients have demonstrated impressive outcomes, in particular, those with RRMM.

\section{Immunotherapy}

In the spectrum of new agents that are being developed and tested as potential candidates for the treatment of MM, monoclonal antibodies (mAbs) targeting highly expressed tumor antigens have emerged as a promising strategy. Targeted immunotherapy with mAbs is seen as a revolutionary approach to the successful treatment of many forms of cancer. mAbs designed to act against cell surface proteins such as CD20 (rituximab), HER2 (trastuzumab), and cytokines such as VEGF (bevacizumab) have been critical in the therapeutic strategies for both hematologic malignancies and solid tumors.

The benefit of mAbs stems from their ability to function as anticancer agents through a number of different mechanisms. According to the available evidence, they target cancer cells for destruction by the immune system by engaging immune effector cells via antibody-dependent cellular cytotoxicity or complement-dependent cytotoxicity. Existing research also shows that mAbs are also able to transmit death signals by binding to and cross-linking surface receptors on the target cancer cell or by blocking an activation signal that is necessary for continued cancer growth or viability, thereby inducing apoptosis, as shown in Figure 2. ${ }^{63,64}$

In considering mAbs-based therapy in myeloma, a number of targets have been identified, including components of the bone marrow microenvironment and molecules at the myeloma cell surface. mAbs are able to target the tumor cells directly or indirectly, by interfering with the interaction between the myeloma and the bone marrow stromal cells. ${ }^{64}$

\section{Antibodies against myeloma cells Anti-SLAMF7 (anti-CD2 subset I) mAb}

Elotuzumab is a humanized recombinant monoclonal IgG1 antibody that targets signaling lymphocyte activation molecule (SLAMF7), also known as CSI. SLAMF7 is a cell surface glycoprotein that is highly expressed on MM plasma cells, and to some extent, on lymphocytes, such as NK cells. Elotuzumab is believed to work through several modes of action, including through targeting the antigen SLAMF7 on MM cells, mediating damage through complementdependent cytotoxicity and antibody-dependent cellular cytotoxicity, and activating SLAMF7-expressing NK cells, which increases tumor destruction. ${ }^{63}$

When administered as a single agent, elotuzumab does not exhibit significant clinical activity. However, its use in combination with other drugs produced promising results in a recent Phase III study, ELOQUENT-2. ${ }^{65}$ In this trial, the researchers compared the efficacy and safety of a combination of elotuzumab, lenalidomide, and dexamethasone with treatment with lenalidomide and dexamethasone in patients with relapsed disease. The trial included 646 patients with relapsed or refractory $\mathrm{MM}$ who had previously received a median of two therapies, including BTZ (70\%), thalidomide $(48 \%)$, and lenalidomide (6\%). Moreover, based on their 

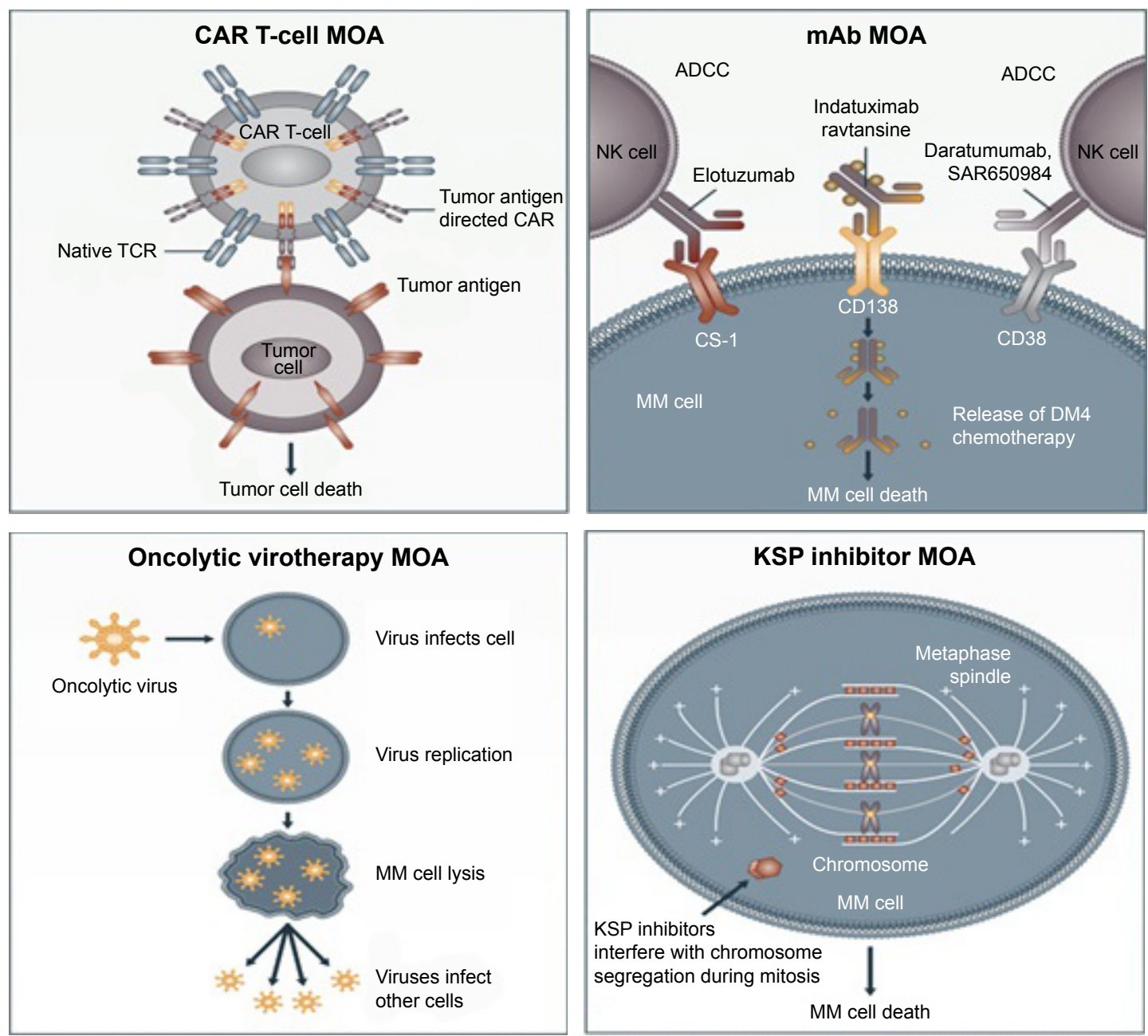

Figure 2 Emerging therapies in MM.

Notes: Current agents under development: CAR T-cells recognize target tumor cells and induce cell death. mAbs with the help of antibody-dependent cell-mediated toxicity induce apoptosis causing cell lethality. Oncolytic virotherapy acts by inducing direct virus-mediated cytotoxicity along with indirect enhancement of host immune responses. KSP inhibitors serve as antimitotic agents in rapidly dividing cells. Reprinted by permission from Macmillan Publisher Ltd: Bone Marrow Transplant. Cornell RF, Kassim AA. Evolving paradigms in the treatment of relapsed/refractory multiple myeloma: increased options and increased complexity. 20I6;5I (4):479-49I. ${ }^{95}$ Copyright 20I6.

Abbreviations: ADCC, antibody-mediated cell toxicity; CAR, chimeric antigen receptor; KSP, kinesin spindle protein; mAb, monoclonal antibody; MM, multiple myeloma; MOA, mechanism of action; NK, natural killer; TCR, T cell receptor.

medical history, $35 \%$ of patients were resistant to their most recent therapy. The median PFS was 19.4 months for patients who received the elotuzumab regimen vs 14.9 months for those who received lenalidomide and dexamethasone alone. However, side effects were more pronounced in the elotuzumab group and included infusion reaction, coughing, fever, diarrhea, fatigue, constipation, decreased appetite, headache, and weight loss. ${ }^{65}$ In December 2015, the FDA approved elotuzumab for use in combination with lenalidomide and dexamethasone in the treatment of patients with MM who have received one to three prior therapies (Table 6).

\section{Anti-CD38 mAbs}

Daratumumab is a human IgG1 $\kappa$ monoclonal antibody that targets CD38, an antigen highly expressed on MM cells. ${ }^{66}$
CD38 is a transmembrane glycoprotein found on lymphoid and myeloid cells, which is involved with calcium flux and signal transduction. In several preclinical studies, daratumumab was identified as having unique potent activity against MM. ${ }^{63,64,66}$ The drug was approved by the FDA in November 2015 for the treatment of MM. This decision was based on the results yielded by the Phase II SIRIUS study involving 106 patients whose disease did not respond to three or more prior therapies, including a PI and an immunomodulatory agent. The overall response to daratumumab was $29 \%$, with three patients experiencing a complete remission during the trial period. The median PFS was 3.7 months, and $65 \%$ of patients survived for at least 1 year. The most common side effects of daratumumab were infusion-related reactions, fatigue, nausea, back pain, fever, and cough. These findings 
established daratumumab as the first monoclonal antibody to have single-agent activity and led to its designation as a bespoke agent. ${ }^{67}$

SAR650984 (SAR, isatuximab) is a humanized IgG1 monoclonal antibody also targeting CD38. In a first-inhuman Phase I dose-escalation trial, 40 patients with heavily pretreated relapsed/refractory MM received SAR at varying doses. According to the preliminary findings, $33 \%$ of patients obtained a clinical benefit and the ORR was $27 \%$ in the entire cohort (based on the results pertaining to all dose groups). The encouraging activity seen in this heavily pretreated population prompted further trials in which the efficacy and safety of SAR650984 alone or in combinations with CFZ and pomalidomide are assessed (Table 6). ${ }^{68-70}$

\section{Conjugated mAbs}

Indatuximab ravtansine (BT-062) is another promising $\mathrm{mAb}$. It is an antibody-drug conjugate, comprising the anti-CD138 chimerized mAb (nBT062) and the maytansinoid DM4 as a cytotoxic agent. It is designed to bind to CD138 on cancer cells, releasing DM4 upon internalization to cause cell death. Numerous clinical trials assessing its safety and efficacy are presently being conducted. Preliminary data from the Phase I dose-escalation portion of a Phase I/IIa study of BT-062 in combination with lenalidomide and dexamethasone were reported at American society of hematology annual meeting. ${ }^{71}$ According to these findings, the ORR among 36 patients evaluated was $78 \%$ (Table 6).

\section{Emerging therapies}

Several preclinical studies suggested that, for rapid replication of tumor cells, a synchronized microtubule assembly and disassembly is required. This led to developing agents that disrupt the mitosis spindle causing cell death. Researchers have identified kinesin spindle protein (KSP) as a key target in mitotic process and were successful in developing a novel drug ARRY-520 (Figure 2). It is a potent inhibitor of KSP, and its efficacy as a single agent has been validated in Phase I studies in patients with RRMM..$^{72,73}$ With these encouraging results, it was pursued in a Phase II study where patients with RRMM were divided into two cohorts. The first cohort received ARRY-520 only and the second cohort received a combination of ARRY-520 and dexamethasone. ORR was $16 \%$ and $22 \%$ in cohorts 1 and 2 , respectively. ${ }^{74}$ Hematologic adverse effects were commonly seen but, most importantly, no PN has been reported. KSP inhibitors hold a promising future for the patients in whom previous therapies have failed to yield benefits, those with RRMM in particular.

\section{Chimeric antigen receptor T-cell therapy}

Recently, chimeric antigen receptor T-cell (CAR T-cell) therapy showed encouraging results in the treatment of MM. CARs are single-chain variable fragments from a monoclonal antibody consisting of intracellular T-cell receptor complex, CD3z chain, or FcR receptor and extracellular domain that recognizes cellsurface-specific antigen. ${ }^{75}$ The second- and third-generation CAR T-cells also include co-stimulatory domains such as CD28. T-cells are genetically transduced through oncoretroviral and lentiviral vectors to express CARs on their surface. These T-cells are then activated to kill target cells either directly or through the engagement of other components of the immune system. ${ }^{75} \mathrm{~A}$ variety of cancers can be targeted by simply substituting various antigen-binding domains on the CARs, encoded by single-chain variable fragments (Figure 2).

In MM, CAR T-cells are directed toward various antigens. In 2013, Carpenter et al conducted an experimental design assessment of B-cell maturation antigen expression in normal human tissues and myeloma cells and demonstrated that adoptive transfer of anti-B-cell maturation antigen-CARexpressing T-cells is a promising strategy in the treatment of MM. ${ }^{76}$ This was followed by several other preclinical and in vivo studies eliciting CAR T-cell therapy as potential therapy for myeloma. ${ }^{77-79}$

Although CAR T-cell therapy appears as a very reassuring strategy in tackling MM, there are certain challenges. These include nonspecific toxicity, as many of the surface molecules are expressed in normal tissues. For example, CD38 targeted in MM is also present in hematopoietic stem cells, NK cells, dendritic cells, pancreatic islet cells, and prostrate; CD138 is present in bronchial epithelia; CD56 in central nervous system neurons. Immunogenicity of CARs, cytokine release syndrome, and immune escape phenomena where tumor cells escape despite the presentation of antigen, are other drawbacks. The technicality and cost further add to these issues. Finally, factors that limit the usage of CAR T-cell therapy include uncertainty of the cell dose, timing of cell infusion and withdrawal, type of immune cell to be used for CAR T-cell delivery, and the durability of CAR T-cell-induced remissions.

\section{Vaccine therapy}

Vaccine therapy is the newest in the category of the emerging therapies in the treatment of MM. Different types of vaccines are utilized, including cell-based vaccines, protein vaccines, idiotype vaccines, and ASCT and donor vaccines. The underlying mechanism of action is based on the fact that vaccines stimulate immune response against tumor-specific 
antigens expressed by MM clone such as WT-1, CS-1, and idiotype protein, thereby attacking MM cells. ${ }^{80}$ Benefit of vaccine therapy is demonstrated in multiple Phase II trials. Lacy et al $^{81}$ compared 27 patients with myeloma after autoHematopoietic stem cell transplant (HCT) who were vaccinated with antigen-presenting cells pulsed with idiotype protein with 124 patients who were not vaccinated after auto-HCT. OS in the vaccine group was 5.3 years vs 3.4 years $(P=0.02)$. Another Phase II trial showed that $24 \%$ patients who showed PR to ASCT showed complete/near complete response following vaccine administration. ${ }^{82}$ A prior study has demonstrated an augmenting effect of IMiDs such as lenalidomide in patients treated with vaccines. ${ }^{83}$ Despite these significant advances made in this arena, it is still in a budding stage and will unfold its tale in the near future with the help of current ongoing research.

\section{Factors associated with treatment selection}

Treatment horizons in MM have expanded significantly over the past decade. However, even with extensive research, prior and current, there is often apprehension in choosing the most appropriate salvage regimen as there are no preset guidelines. ${ }^{84}$ Table 7 summarizes the key aspects when physicians arrive at cross-roads in making decisions on therapies. ${ }^{84}$

\section{Conclusion}

MM is heterogeneous, associated with complex gene abnormalities, and multiple signaling anomalies. Thus, it remains a serious malady, whereby most patients eventually succumb to disease. Several new drugs with novel mechanism of action and less toxic profile have been developed in the past decade, with the potential for use as single agents or in synergy with other treatment modes in MM therapy. Although these therapies produced better responses compared with traditional chemotherapy in controlled trials, the efficacy and safety of these novel drugs have not been sufficiently investigated, making it difficult to determine whether one agent is superior to another. Consequently, selecting the most appropriate initial management remains a challenge.

In particular, when treating relapsing patients, one of the most important goals is enhancing their quality of life (QoL). However, this kind of evaluation is often lacking in many studies investigating these novel therapies. In addition, as QoL is a subjective measure, developing tools for accurate assessment remains a challenge. Moreover, the discussions presented earlier revealed that most newly developed drugs target specific mechanisms of neoplastic cell growth. Thus, when considering their efficacy, it is important to highlight that myeloma is a highly heterogeneous disease, whereby neoplastic plasma cells can use several metabolic pathways in order to maximize growth potential. In addition, available evidence also indicates that different neoplastic clones may emerge in different phases of disease and it is possible that each clone has a different profile of drug sensitivity. Hence, it is conceivable that each of the drugs that have emerged as potential MM treatment candidates is effective in a subgroup of patients only and exhibits benefits only during a specific phase of disease. Given these limitations, the challenge for future investigations is identifying the specific range and timing of activity of each new drug.

Finally, it is essential for clinicians to recognize that the mechanism of action of these new drugs is typically

Table 7 Factors to consider in choosing salvage regimen

\begin{tabular}{|c|c|}
\hline $\begin{array}{l}\text { Patient-related } \\
\text { factors }\end{array}$ & $\begin{array}{l}\text { - Assess for comorbidities such as diabetes and heart failure especially in elderly population as they are more vulnerable to } \\
\text { - Arug toxicity } \\
\text { - Assess for renal impairment as many novel drugs need adjustment. BTZ and CFZ do not need adjustment while LEN } \\
\text { - Assess for hepatic impairment. Cautious use of PI and POM is recommended }\end{array}$ \\
\hline $\begin{array}{l}\text { Treatment-related } \\
\text { factors }\end{array}$ & $\begin{array}{l}\text { - Assess prior received therapies and toxicity associated with them. Use combination drugs that exhibit sensitization and } \\
\text { synergistic activity such as HDACi along with PI, and PI with LEN } \\
\text { - Avoid the same drugs that caused toxicity. If PN is an issue, choose CFZ instead of BTZ in salvage regimens } \\
\text { - Duration of prior response is always critical when deciding on salvage regimens. Intensive therapy is used if relapse } \\
\text { occurs within last } 12 \text { months of prior therapy with triple regimen (PI, IMiDs with DEX) }\end{array}$ \\
\hline $\begin{array}{l}\text { Disease-related } \\
\text { factors }\end{array}$ & $\begin{array}{l}\text { - Clinicians should know about high-risk cytogenetics. Most importantly, } \mathrm{t}(4 ; 14) \text { and del(I7p). BTZ has better prognosis in } \\
\text { both } \mathrm{t}(4 ; 14) \text { and del(I7p). POM showed longer survival in del(I7p) patients than in } \mathrm{t}(4 ; 14) \text {. Several secondary variations in } \\
\text { genetics have been identified (MYC dysregulation, del(I8p)). However, studies are underway in elucidating the benefit of } \\
\text { novel drugs in patients harboring high-risk genetics }\end{array}$ \\
\hline $\begin{array}{l}\text { Availability of } \\
\text { clinical trial }\end{array}$ & - Always consider enrolling patient in clinical trial if they are eligible \\
\hline
\end{tabular}

Note: Data from Nooka et al. ${ }^{84}$

Abbreviations: BTZ, bortezomib; CFZ, carfilzomib; DEX, dexamethasone; HDACi, histone deacytalase inhibitors; IMiDs, immunomodulatory drugs; LEN, lenalidomide; $\mathrm{Pl}$, proteasome inhibitor; POM, pomalidomide; PN, peripheral neuropathy. 
different from that exhibited by chemotherapeutic drugs. Thus, when determining the optimal dose and identifying patients who would benefit the most from these novel therapies, it is unwise to draw parallels with traditional treatment modalities. In addition, when deciding whether to use these emerging agents, the proven efficacy of "old" chemotherapy against myeloma should not be overlooked. In many cases, it is likely that the patient would benefit the most from adding new treatments to the chemotherapy. Thus, the goal should not necessarily be to find completely new treatment options, but rather work on establishing the most advantageous combination of traditional and novel therapies.

As a general rule, physicians are advised to choose therapy based on patient's age, comorbidities, cytogenetic abnormalities, and locally available drugs, while aiming to enhance QoL. However, owing to rapid medical advances, they should also keep abreast with the latest developments and ongoing clinical trials, as these may also be potential avenues to pursue with their patients, if eligible for inclusion. Based on the discussions presented in this work, it can be concluded that the key to MM treatment may be combining various medications with different mechanisms of action to target not only the MM cells but also the tumor microenvironment.

\section{Disclosure}

The authors report no conflicts of interest in this work.

\section{References}

1. Katzel JA, Hari P, Vesole DH. Multiple myeloma: charging toward a bright future. CA Cancer J Clin. 2007;57(5):301-318.

2. National Cancer Institute. SEER Cancer Statistics Review, 1975-2004. Bethesda, MD: National Cancer Institute; 2003.

3. Kumar SK, Lee JH, Lahuerta JJ, et al; International Myeloma Working Group. Risk of progression and survival in multiple myeloma relapsing after therapy with IMiDs and bortezomib: a multicenter international myeloma working group study. Leukemia. 2012;26(1):149-157.

4. Pulte D, Redaniel MT, Brenner H, Jansen L, Jeffreys M. Recent improvement in survival of patients with multiple myeloma: variation by ethnicity. Leuk Lymphoma. 2014;55(5):1083-1089.

5. Barlogie B, Tricot G, Anaissie E, et al. Thalidomide and hematopoieticcell transplantation for multiple myeloma. N Engl J Med. 2006;354(10): 1021-1030.

6. Kumar SK, Therneau TM, Gertz MA, et al. Clinical course of patients with relapsed multiple myeloma. Mayo Clin Proc. 2004;79(7): 867-874.

7. International Myeloma Working Group. Criteria for the classification of monoclonal gammopathies, multiple myeloma and related disorders: a report of the International Myeloma Working Group. Br J Haematol. 2003;121(5):749-757.

8. Rajkumar SV, Dimopoulos MA, Palumbo A, et al. International myeloma working group updated criteria for the diagnosis of multiple myeloma. Lancet Oncol. 2014;15(12):e538-e548.

9. Dispenzieri A, Rajkumar SV, Gertz MA, et al. Treatment of newly diagnosed multiple myeloma based on mayo stratification of myeloma and risk-adapted therapy (mSMART): consensus statement. Mayo Clin Proc. 2007;82(3):323-341.
10. Stewart AK, Bergsagel PL, Greipp PR, et al. A practical guide to defining high-risk myeloma for clinical trials, patient counseling and choice of therapy. Leukemia. 2007;21(3):529-534.

11. Rajan AM, Rajkumar SV. Interpretation of cytogenetic results in multiple myeloma for clinical practice. Blood Cancer J. 2015;5:e365.

12. Vu T, Gonsalves W, Kumar S, et al. Characteristics of exceptional responders to lenalidomide-based therapy in multiple myeloma. Blood Cancer J. 2015;5:e363.

13. Sonneveld P, Schmidt-Wolf IG, van der Holt B, et al. Bortezomib induction and maintenance treatment in patients with newly diagnosed multiple myeloma: results of the randomized phase III HOVON-65/ GMMG-HD4 trial. J Clin Oncol. 2012;30(24):2946-2955.

14. Cavo M, Tacchetti P, Patriarca F, et al; GIMEMA Italian Myeloma Network. Bortezomib with thalidomide plus dexamethasone compared with thalidomide plus dexamethasone as induction therapy before, and consolidation therapy after, double autologous stem-cell transplantation in newly diagnosed multiple myeloma: a randomised phase 3 study. Lancet. 2010;376(9758):2075-2085.

15. Greenberg AJ, Rajkumar SV, Therneau TM, Singh PP, Dispenzieri A, Kumar SK. Relationship between initial clinical presentation and the molecular cytogenetic classification of myeloma. Leukemia. 2014;28(2): 398-403.

16. Kuiper R, Broyl A, de Knegt Y, et al. A gene expression signature for high-risk multiple myeloma. Leukemia. 2012;26(11):2406-2413.

17. van Laar R, Flinchum R, Brown N, et al. Translating a gene expression signature for multiple myeloma prognosis into a robust high-throughput assay for clinical use. BMC Med Genomics. 2014;7:25.

18. Kortüm KM, Langer C, Monge J, et al. Targeted sequencing using a 47 gene multiple myeloma mutation panel $(\mathrm{M}(3) \mathrm{P})$ in $-17 \mathrm{p}$ high risk disease. Br J Haematol. 2015;168(4):507-510.

19. Kortüm KM, Langer C, Monge J, et al. Longitudinal analysis of 25 sequential sample-pairs using a custom multiple myeloma mutation sequencing panel (M(3)P). Ann Hematol. 2015;94(7): 1205-1211.

20. Rajkumar SV, Harousseau JL, Durie B, et al; International Myeloma Workshop Consensus Panel 1. Consensus recommendations for the uniform reporting of clinical trials: report of the international myeloma workshop consensus panel 1. Blood. 2011;117(18): 4691-4695.

21. Lecker SH, Goldberg AL, Mitch WE. Protein degradation by the ubiquitin-proteasome pathway in normal and disease states. J Am Soc Nephrol. 2006;17(7):1807-1819.

22. Traenckner EB, Wilk S, Baeuerle PA. A proteasome inhibitor prevents activation of NF-kappa B and stabilizes a newly phosphorylated form of I kappa B-alpha that is still bound to NF-kappa B. EMBO J. 1994;13(22):5433-5441.

23. Moriya S, Komatsu S, Yamasaki K, et al. Targeting the integrated networks of aggresome formation, proteasome, and autophagy potentiates ER stress-mediated cell death in multiple myeloma cells. Int J Oncol. 2015;46(2):474-486.

24. Myung J, Kim KB, Crews CM. The ubiquitin-proteasome pathway and proteasome inhibitors. Med Res Rev. 2001;21(4):245-273.

25. Hideshima T, Richardson P, Chauhan D, et al. The proteasome inhibitor PS-341 inhibits growth, induces apoptosis, and overcomes drug resistance in human multiple myeloma cells. Cancer Res. 2001;61(7): 3071-3076.

26. Richardson PG, Xie W, Jagannath S, et al. A phase 2 trial of lenalidomide, bortezomib and dexamethasone in patients with relapsed and relapsed/refractory myeloma. Blood. 2014;123:1461-1469.

27. Lü S, Wang J. The resistance mechanisms of proteasome inhibitor bortezomib. Biomark Res. 2013;1(1):13.

28. Siegel DS, Martin T, Wang M, et al. A phase 2 study of single-agent carfilzomib (PX-171-003-A1) in patients with relapsed and refractory multiple myeloma. Blood. 2012;120(14):2817-2825.

29. Dick LR, Fleming PE. Building on bortezomib: second-generation proteasome inhibitors as anti-cancer therapy. Drug Discov Today. 2010; 15(5-6):243-249. 
30. Jagannath S, Vij R, Stewart AK, et al. An open-label single-arm pilot phase II study (PX-171-003-A0) of low-dose, single-agent carfilzomib in patients with relapsed and refractory multiple myeloma. Clin Lymphoma Myeloma Leuk. 2012;12(5):310-318.

31. Vij R, Wang M, Kaufman JL, et al. An open-label, single-arm, phase 2 (PX-171-004) study of single-agent carfilzomib in bortezomib-naive patients with relapsed and/or refractory multiple myeloma. Blood. 2012;119(24):5661-5670.

32. Stewart AK, Rajkumar SV, Dimopoulos MA, et al; ASPIRE Investigators. Carfilzomib, lenalidomide, and dexamethasone for relapsed multiple myeloma. $N$ Engl J Med. 2015;372(2):142-152.

33. Dimopoulous MA, Moreau P, Paloumbo A, et al. Carfilzomib and dexamethasone $(K d)$ vs bortezomib and dexamethasone $(V d)$ in patients (pts) with relapsed multiple myeloma (RMM): results from the phase III study ENDEAVOR. ASCO University 2015. Available from: http:// meetinglibrary.asco.org/content/150736-156. Accessed July 14, 2016.

34. Sonneveld P, Hacker E, Zweegman S, et al. Carfilzomib combined with thalidomide and dexamethasone (CARTHA-DEX) as induction treatment prior to high-dose melphalan (HDM) in newly diagnosed patients with multiple myeloma (MM). A trial of the European myeloma network EMN. 53rd Annual Meeting and Exposition of the American Society of Hematology. 2011.

35. Wang M, Martin T, Bensinger W, et al. Phase 2 dose-expansion study (PX-171-006) of carfilzomib, lenalidomide, and low-dose dexamethasone in relapsed or progressive multiple myeloma. Blood. 2013;122(18): 3122-3128.

36. ClinicalTrials.gov. Bortezomib or carfilzomib with lenalidomide and dexamethasone in treating patients with newly diagnosed multiple myeloma(ENDURANCE). NCT01863550.

37. Richardson PG, Spencer A, Cannell P, et al. Phase I clinical evaluation of twice weekly marizomib (NPI-0052), a novel proteasome inhibitor, in patients with relapsed/refractory multiple myeloma. 53rd ASH Annual Meeting and Exposition. 2011.

38. Das DS, Ray A, Song Y, et al. Synergistic anti-myeloma activity of the proteasome inhibitor marizomib and the $\operatorname{IMiD}((\mathrm{R}))$ immunomodulatory drug pomalidomide. Br J Haematol. 2015;171(5):798-812.

39. Moreau P, Masszi T, Grzasko N, et al. Oral ixazomib, lenalidomide, and dexamethasone for multiple myeloma. $N$ Engl J Med. 2016;374(17):1621-1634.

40. Papadopoulos PK, Medelson D, Tolcher AW, et al. A phase I, openlabel, dose-escalation study of the novel oral proteasome inhibitor (PI) ONX 0912 in patients with advanced refractory or recurrent solid tumors. ASCO Annual Meeting Abstracts. 2011.

41. Piva R, Ruggeri B, Williams M, et al. CEP-18770: a novel, orally active proteasome inhibitor with a tumor-selective pharmacologic profile competitive with bortezomib. Blood. 2008;111(5):2765-2775.

42. Zhang J, Wu P, Hu Y. Clinical and marketed proteasome inhibitors for cancer treatment. Curr Med Chem. 2013;20(20):2537-2551.

43. Reske T, Fulciniti M, Munshi NC. Mechanism of action of immunomodulatory agents in multiple myeloma. Med Oncol. 2010;27(suppl 1): S7-S13.

44. Hideshima T, Chauhan D, Shima Y, et al. Thalidomide and its analogs overcome drug resistance of human multiple myeloma cells to conventional therapy. Blood. 2000;96(9):2943-2950.

45. National Cancer Institute. FDA Approval of Thalidomide. 2006 Available from: http://www.cancer.gov/about-cancer/treatment/drugs/ fda-thalidomide. Accessed May 1, 2016.

46. Palumbo A, Rajkumar SV, Dimopoulos MA, et al; International Myeloma Working Group. Prevention of thalidomide- and lenalidomide-associated thrombosis in myeloma. Leukemia. 2008;22(2): 414-423.

47. Dimopoulos M, Spencer A, Attal M, et al; Multiple Myeloma (010) Study Investigators. Lenalidomide plus dexamethasone for relapsed or refractory multiple myeloma. N Engl J Med. 2007;357(21):2123-2132.

48. Weber DM, Chen C, Niesvizky R, et al. Multiple Myeloma (009) study investigators. Lenalidomide plus dexamthasone for relapsed multiple myeloma in north America. N Engl J Med. 2007;357(21):2133-2142.
49. Attal M, Lauwers-Cances V, Marit G, et al; IFM Investigators. Lenalidomide maintenance after stem-cell transplantation for multiple myeloma. N Engl J Med. 2012;366(19):1782-1791.

50. Clark SM, Steinbach A, Clemmons AB. Pomalidomide for the treatment of multiple myeloma. J Adv Pract Oncol. 2014;5(1):51-56.

51. Richardson PG, Siegel DS, Vij R, et al. Pomalidomide alone or in combination with low-dose dexametha- sone in relapsed and refractory multiple myeloma: a randomized phase 2 study. Blood. 2014;123:1826-1832.

52. San Miguel J, Weisel K, Moreau P, et al. Pomalidomide plus low-dose dexamethasone versus high-dose dexamethasone alone for patients with relapsed and refractory multiple myeloma (MM-003): a randomised, open-label, phase 3 trial. Lancet Oncol. 2013;14(11):1055-1066.

53. Maes K, Menu E, Van Valckenborgh E, Van Riet I, Vanderkerken K, De Bruyne E. Epigenetic modulating agents as a new therapeutic approach in multiple myeloma. Cancers (Basel). 2013;5(2):430-461.

54. Choudhary C, Kumar C, Gnad F, et al. Lysine acetylation targets protein complexes and co-regulates major cellular functions. Science. 2009; 325(5942):834-840.

55. Richardson PG, Laubach JP, Lonial S. Panobinostat: a novel pandeacetylase inhibitor for the treatment of relapsed or relapsed and refractory multiple myeloma. Expert Rev Anticancer Ther. 2015; 15(9):1121.

56. Simms-Waldrip T, Rodriguez-Gonzalez A, Lin T, Ikeda AK, Fu C, Sakamoto KM. The aggresome pathway as a target for therapy in hematologic malignancies. Mol Genet Metab. 2008;94(3):283-286.

57. Lee JY, Koga H, Kawaguchi Y, et al. HDAC6 control autophagosome maturation essential for ubiquitin-selective quality control autophagy. EMBO J. 2010;29(5):969-980.

58. Richardson PG, Hungria Vania TM, Yoon SS, et al. Panorama 1: A randomized, double-blind, phase 3 study of panobinostat or placebo plus bortezomib and dexamethasone in relapsed or relapsed and refractorymultiple myeloma. ASCO University. Available from: http://meetinglibrary. asco.org/content/125334-144. Accessed July 14, 2016.

59. Richardson PG, Schlossman RL, Alsina M, et al. PANORAMA 2: panobinostat in combination with bortezomib and dexamethasone in patients with relapsed and bortezomib-refractory myeloma. Blood. 2013;122(14):2331-2337.

60. Siegel DS, Richardson P, Dimopoulos M, et al. Vorinostat in combination with lenalidomide and dexamethasone in patients with relapsed or refractory multiple myeloma. Blood Cancer J. 2014;4:e182.

61. Dimopoulos M, Siegel DS, Lonial S, et al. Vorinostat or placebo in combination with bortezomib in patients with multiple myeloma (VANTAGE 088): a multicentre, randomised, double-blind study. Lancet Oncol. 2013;14(11):1129-1140.

62. Siegel DS, Dimopoulos M, Yoon SS, et al. Vantage 095: vorinostat in combination with bortezomib in salvage multiple myeloma patients: final study results of a global phase 2b trial. 53rd American Society of Hematology: Annual Meeting and Exposition. 2011.

63. Sondergeld P, van de Donk NW, Richardson PG, Plesner T. Monoclonal antibodies in myeloma. Clin Adv Hematol Oncol. 2015;13(9): 599-609.

64. Sherbenou DW, Behrens CR, Su Y, Wolf JL, Martin TG 3rd, Liu B. The development of potential antibody-based therapies for myeloma. Blood Rev. 2015;29(2):81-91.

65. Lonial S, Dimopoulos M, Palumbo A, et al; ELOQUENT-2 Investigators. Elotuzumab therapy for relapsed or refractory multiple myeloma. N Engl J Med. 2015;373(7):621-631.

66. De Weers M, Tai YT, van der Veer MS, et al. Daratumumab, a novel therapeutic human CD38 monoclonal antibody, induces killing of multiple myeloma and other hematological tumors. J Immunol. 2011;186(3): 1840-1848.

67. Lonial S, Weiss BM, Usmani SZ, et al. Phase II study of daratumumab (DARA) monotherapy in patients with $\geq 3$ lines of prior therapy or double refractory multiple myeloma (MM): 54767414MMY2002 (Sirius). ASCO University. Available from: http://meetinglibrary.asco. org/content/150339-156. Accessed July 14, 2016. 
68. Martin TG, Hsu K, Strickland SA, et al. A phase I trial of SAR650984, a CD38 monoclonal antibody, in relapsed or refractory multiple myeloma. ASCO University. Available from: http://meetinglibrary. asco.org/content/129808-144. Accessed July 14, 2016.

69. ClinicalTrials.gov. SAR650984 in Combination With Carfilzomib for Treatment of Relapsed or Refractory Multiple Myeloma. NCT02332850.

70. ClinicalTrials.gov. SAR650984, Pomalidomide and Dexamethasone in Combination in RRMM Patients (PomdeSAR). NCT02283775.

71. Kelly KR, Chanan-Khan A, Somlo G, et al. Indatuximab Ravtansine (BT062) In Combination With Lenalidomide and Low-Dose Dexamethasone In Patients With Relapsed and/Or Refractory Multiple Myeloma: Clinical Activity In Len/Dex-Refractory Patients. ASH Annual Meeting. 2013.

72. Shah JJ, Zonder JA, Cohen A, et al. ARRY-520 Shows Durable Responses in Patients with Relapsed/Refractory Multiple Myeloma in a Phase 1 Dose-Escalation Study. 53rd ASH Annual Meeting and Exposition. 2011.

73. Woessner RTB, Cox A, Rana S, Walker D, Lee PA. Combination of the KSP inhibitor ARRY-420 with bortezomib or revlimid causes sustained tumor regressions and significantly increased time to regrowth in models of multiple myeloma. 51st ASH Annual Meeting and Exposition. 2009.

74. Shah JJ, Zonder JA, Cohen A, et al. The novel KSP inhibitor ARRY520 is active both with and without low dose dexamethasone in patients with multiple myeloma refractory to bortezomib and lenalidomide. Results from phase 2 study. ASH Annual Meeting Abstracts. Vol.120. 2012:449.

75. Firor AE, Jares A, Ma Y. From humble beginnings to success in the clinic: Chimeric antigen receptor-modified T-cells and implications for immunotherapy. Experimental biology and medicine. 2015;240:1087-1098.

76. Sadelain M, Brentjens R, Riviere I. The basic principles of chimeric antigen receptor design. Cancer Discov. 2013;3(4):388-398.

77. Carpenter RO, Evbuimwam MO, Pittaluga S, et al. B-cell maturation antigen is promising target for adoptive T-cell therapy of multiple myeloma. Clin Cancer Res. 2013;19(8):2048-2060.

78. Peinert S, Prince HM, Guru PM, et al. Gene modified T cells as immunotherapy for multiple myeloma and acute myeloid leukemia expressing the Lewis Y antigen. Gene Ther. 2010;17(5):678-686.

79. Chu J, Deng Y, Benson DM, et al. CS1-specific chimeric antigen receptor(CAR)-engineered natural killer cells enhance in vitro and in vivo antitumor activity against human multiple myeloma. Leukemia. 2014; 28(4):917-927.

80. Schuberth PC, Jakka G, Jensen SM, et al. Effector memory and central memory NY-ESO-1-specific re-directed T cells for treatment of multiple myeloma. Gene Ther. 2013;20(4):386-395.

81. Lacy MQ, Mandrekar S, Dispenzieri A, et al. Idiotype pulsed antigen presenting cells for autologous transplantation of multiple myeloma may be associated with prolonged survival. Am J Hematol. 2009; 84(12):799-802.
82. Katz T, Avivi I, Benyamini N, Rosenblatt J, Avigan D. Dendritic cell cancer vaccines: from the bench to the bedside. Rambam Maimonides Med J. 2014;5(4):e0024.

83. Noonan K, Rudraraju L, Ferguson A, et al. Lenalidomide-Induced Immunomodulation in Multiple Myeloma: Impact on Vaccines and Antitumor Responses. Clin can research. 2012;18(5)1426-1434.

84. Nooka AK, Kastritis E, Dimopoulos MA, Lonial S. Treatment option for relapsed and refractory multiple myeloma. Blood. 2015; 125(20):3085-3099.

85. Jagannath S, Barlogie B, Berenson J, et al. A phase 2 study of two doses of bortezomib in relapsed or refractory myeloma. Br J Haematol. 2004;127:165-172.

86. Richardson PG, Barlogie B, Berenson B, et al. A phase 2 study of bortezomib in Relapsed, Refractory Myeloma. $N$ Engl J Med. 2003;348:2609-2617.

87. Richardson PG, Sonneveld P, Schuster MW, et al. Bortezomib or highdose dexamethasone for relapsed multiple myeloma. $N$ Engl J Med. 2005;352:2487-2498.

88. Pineda-Roman M, Zangari M, Van Rhee F, et al. VTD combination therapy with bortezomib-thalidomide-dexamethasone is highly effective in advanced and refractory multiple myeloma. Leukemia. 2008;22:1419-1427.

89. Shah JJ, Stadtmauer EA, Abonour R, et al. Phase I/II dose expansion of a multi-center trial of carfilzomib and pomalidomide with dexamethasone (Car-Pom-D) in patients with relapsed/refractory multiple myeloma. ASH Annual Meeting Abstract. 2013.

90. Baz R, Martin TG, Alsina M, et al. Pomalidomide, cyclophosphamide, and dexamethasone is superior to pomalidomide and dexamethasone in relapsed and refractory myeloma: results of a multicenter randomized phase II study. 56th ASH Annual Meeting and Exposition. 2014.

91. Richardson PG, Hoffmeister CC, Seigel DS, et al. MM-005: a phase I trial of pomalidomide, bortezomib, and low-dose dexamethasone (PVD) in relapsed and/or refractory multiple myeloma (RRMM). ASCO Annual Meeting. 2013.

92. Richardson PG, Bensmaine A, Doerr T, Wang J, Zaki MH. MM-007: A phase 3 trial comparing the efficacy and safety of pomalidomide (POM), bortezomib (BORT), and low-dose dexamethasone (LoDEX [PVD]) versus BORT and LoDEX (VD) in subjects with relapsed or refractory multiple myeloma (RRMM). J Clin Oncol 33. 2015;(suppl; abstr TPS8610).

93. ClinicalTrials.gov. Study of T Cell Targeting B-Cell Maturation Antigen for Previously Treated Multiple Myeloma. ClinicalTrials.gov Identifier: NCT02215967.

94. ClinicalTrials.gov. A Phase II Trial of Oncolytic Virotherapy by Systemic Administration of Edmonston Strain of Measles Virus. ClinicalTrials.gov Identifier: NCT02192775.

95. Cornell RF, Kassim AA. Evolving paradigms in treatment of relapsed/ refractory multiple myeloma:increased options and increased complexity. Bone Marrow Transplant. 2016;51(4):479-491.
OncoTargets and Therapy

\section{Publish your work in this journal}

OncoTargets and Therapy is an international, peer-reviewed, open access journal focusing on the pathological basis of all cancers, potential targets for therapy and treatment protocols employed to improve the management of cancer patients. The journal also focuses on the impact of management programs and new therapeutic agents and protocols on

\section{Dovepress}

patient perspectives such as quality of life, adherence and satisfaction. The manuscript management system is completely online and includes a very quick and fair peer-review system, which is all easy to use. Visit $\mathrm{http}: / /$ www.dovepress.com/testimonials.php to read real quotes from published authors. 